\title{
Prevalence of Lifestyle Risk Factors in Myotonic Dystrophy Type 1
}

\author{
Cynthia Gagnon, Maud-Christine Chouinard, Luc Laberge, Diane Brisson, \\ Daniel Gaudet, Mélissa Lavoie, Nadine Leclerc, Jean Mathieu
}

\begin{abstract}
Background: The prevalence of unhealthy lifestyle habits such as smoking has seldom been described in neuromuscular disorders, including myotonic dystrophy type 1 (DM1). However, it is essential to document the unhealthy lifestyle habits as they can exacerbate existing impairments and disabilities. The objectives are: 1) To determine the prevalence of risk factors among individuals with DM1; 2) To compare the prevalence among classic and mild phenotypes. Method: A survey was done on a sample of two-hundred (200) patients with DM1 as part of a larger study. Lifestyle risk factors included being overweight or obese, tobacco smoking, illicit drug use, excessive alcohol consumption and physical inactivity. A registered nurse administered the validated public health survey. Categorization of risk factors were based on national standards and compared with provincial and regional prevalences. Results: $50 \%$ of DM1 patients were overweight or obese, $23.6 \%$ were regular smokers, and $76 \%$ were physically inactive. Except for overweight and obesity, significant differences were observed between patients with classic and mild phenotypes for all the other lifestyle risk factors: those with the classic phenotype being more often regular smokers, consuming more often illicit drugs and being less physically active. Conclusions: The results of this study will provide guidance for the development of better adapted and focussed health promotion interventions in the future.
\end{abstract}

RÉSUMÉ: Prévalence des facteurs de risque liés aux habitudes de vie dans la dystrophie myotonique de type 1. Contexte : La prévalence d'habitudes de vie non favorables à la santé comme le tabagisme a rarement été décrite dans les maladies neuromusculaires dont la dystrophie myotonique de type 1 (DM1). Cependant, il est essentiel de les documenter puisse qu'elles peuvent exacerber les déficiences et les incapacités. Les objectifs de l'étude étaient de déterminer la prévalence de facteurs de risque chez les patients atteints de DM1 et de comparer leur prévalence chez les patients qui présentent un phénotype classique et léger. Méthode : L'étude porte sur un échantillon de deux cent patients atteints de DM1, dans le cadre d'une étude plus vaste. Les facteurs de risque liés aux habitudes de vie incluaient l'embonpoint ou l'obésité, le tabagisme, l'utilisation de drogues illégales, la consommation d'alcool et la sédentarité. Une infirmière administrait le questionnaire de santé publique. Les facteurs de risque étaient classés selon les standards nationaux et leur prévalence était comparée aux prévalences provinciales et régionales. Résultats : Cinquante pourcent des patients atteints de DM1 souffraient d'embonpoint ou étaient obèses, 23,6\% étaient fumeurs et $76 \%$ étaient sédentaires. Des différences significatives ont été observées entre les patients atteints du phénotype classique et ceux du phénotype léger pour tous les facteurs de risque liés aux habitudes de vie, sauf pour l'embonpoint et l'obésité : il y avait plus de fumeurs réguliers chez ceux qui présentaient le phénotype classique, plus d'utilisateurs de drogues illégales et ils étaient moins actifs. Conclusions : Les résultats de notre étude pourront servir de guide dans l'élaboration d'interventions de promotion de la santé qui sont plus ciblées et mieux adaptées.

Can J Neurol Sci. 2013; 40: 42-47

Myotonic dystrophy type 1 (DM1) is the most common adultonset muscular dystrophy ${ }^{1,2}$. DM1 results from an unstable CTG-repeat expansion in the 3' untranslated region of a myotonic dystrophy protein kinase gene on chromosome $19 q 13.3^{3}$. The [CTG]n expansion responsible for DM1 can vary from 50 to over 1000 repeats, leading to phenotypic variability and different age at onset. Myotonic dystrophy type 1 is a progressive and pleiotropic disease that can affect several systems including the muscular, respiratory, cardiac, endocrine, ocular and central nervous systems ${ }^{4}$. Decreased strength $^{5}$, fatigue $^{6}$ and decreased executive function ${ }^{7}$ are the impairments in DM1 with the most significant impact on quality of life and social participation ${ }^{6,8,9}$. DM1 is also associated with difficulty in the accomplishment of several daily activities and social roles ${ }^{10}$ including mobility issues ${ }^{11}$ and low educational attainment ${ }^{12,13}$. Individuals with DM1 live in a distinctive environment characterized by poverty, lack of social support and poor housing ${ }^{12,13}$. A more holistic approach in the management of such a chronic complex disabling disease has been recommended ${ }^{11,14}$ and should also be geared towards strengthening the remaining health potential of patients ${ }^{15,16}$.

One way to reach this goal is to integrate health promotion principles as an essential part of the management of DM1 patients. Health promotion may be conceived as "the science or art of helping individuals to change their lifestyle and to move

From the Faculty of Medicine and Health Sciences (CG, ML, JM), Université de Sherbrooke; Groupe de recherche interdisciplinaire sur les maladies neuromusculaires (GRIMN), Neuromuscular Clinic, (CG, MCC, ML, NL, JM) Centre de réadaptation en déficience physique de Jonquière, Centre de santé et de services sociaux de Jonquière; ÉCOBES Recherche et transfert (LL), Cégep de Jonquière; University of Montreal

Community Genomic Medicine Center (DB, DG), Department of medicine, Université de Montréal; Health Science department (MCC, LL), Université du Québec à

Chicoutimi, Québec, Canada.

Received January 17, 2012. Final Revisions Submitted August 20, 2012. Correspondence to: Cynthia Gagnon, Faculty of Medicine and Health Sciences,

Université de Sherbrooke, Centre de santé et de services sociaux de Jonquière, 2230 de l'Hôpital, C.P. 1200, Jonquière, Québec G7X 7X2, Canada.

Email: cynthia.gagnon4@usherbrooke.ca. 
towards a state of optimal health". Lifestyle change can be facilitated through a combination of efforts to increase awareness, change behaviour, and create environments that support good health practice" ${ }^{17}$. It may also be described as "activities directed toward increasing the level of well-being and actualizing the health potential of individuals, families, and communities and societies" ${ }^{18}$. Healthy lifestyle change has been advocated as an essential element in the chronic patient rehabilitation process ${ }^{19}$ and was congruent with rehabilitation goals that aim to enhance quality of life through maintaining optimal social participation and health ${ }^{15}$. However, this approach has been poorly developed ${ }^{20}$ for rehabilitation populations affected with chronic diseases ${ }^{21,22}$.

One aspect of health promotion is the awareness of modifiable lifestyle risk factors. Tobacco smoking, insufficient physical activity and poor nutrition are key risk factors not only for cardiovascular complications but also for other aspects of chronic neuromuscular disorders such as DM1.

The prevalence of unhealthy lifestyle risk factors is influenced by poverty and people further down the social ladder usually run at least twice the risk of serious illness and premature death as those near the top ${ }^{23}$. It is acknowledged that the poor social and economic status typically prevailing in DM1 is related to the severity of the disease ${ }^{12}$. More particularly, each additional 100 CTG repeats was found to increase the odds of relying on social assistance by about $35 \%$ and of having low social support by about $22 \%$. The chances of experiencing socioeconomic deprivation are loaded heavily against more affected patients with DM1.

A small study concluded that people with neuromuscular disorders are at high-risk of developing chronic diseases resulting from obesity and a sedentary lifestyle ${ }^{24}$. However, a more exhaustive clinical picture of the prevalence of these health lifestyle risk factors among DM1 patients is needed. Four different clinical phenotypes are recognized in DM1 according to age of onset in conjunction with [CTG]n repeats: congenital, childhood, classic (adult) and mild (late-onset) ${ }^{25}$. The severity of the disease and its impacts on social participation vary greatly between these phenotypes ${ }^{10}$. Since the risk of poverty is related to the severity of the disease and socio-economic conditions of individuals influence their lifestyle risk factors, we anticipate that the prevalence of such lifestyle risk factors will vary among the DM1 phenotypes.

Thus, the objectives of the study are: 1) To determine the prevalence of risk factors among individuals with DM1;2) To compare the prevalence of risk factors among classic and mild phenotype. This will guide the development of more adapted and focussed health promotion interventions in the future.

\section{METHODS \\ Participants}

Two-hundred (200) patients with DM1 were randomly selected as described elsewhere ${ }^{12}$ from a subset of 416 DM1 individuals listed at the Neuromuscular Clinic (NMC) of the Centre de santé et des services sociaux de Jonquière (Quebec, Canada). Inclusion criteria were: age $>18$ years, having a molecular confirmation of DM1 diagnosis and being able to provide informed consent. For the purpose of this study, subjects were classified as having the mild phenotype of the disease if they presented at least two or more of the three following criteria: ${ }^{9}$ 1) CTG < 200; 2) Muscular Impairment Rating Scale $(\text { MIRS })^{26}$ score of 1 (No muscular impairment) or 2 (Minimal signs) reported in the medical chart, and; 3) age at onset of symptoms $\geq 40$ years. All other subjects were classified as having the classic phenotype. Patients with the congenital or childhood DM1 phenotypes were excluded from this study. This study was conducted with the Institutional Review Board (IRB) approval from the Centre de Santé et de Services Sociaux de Chicoutimi.

\section{Data Collection}

Demographics: Information was gathered regarding age, sex, annual familial income, and educational level. CTG repeat was determined using Southern blot analysis. ${ }^{12}$

Lifestyle risk factors: A registered nurse administered in person the validated provincial public health survey for tobacco smoking, illicit drug use, alcohol consumption and physical inactivity ${ }^{27,28}$. National guidelines were used for categorizing risk factors for alcohol consumption ${ }^{29}$. In addition, a list of reasons preventing them from exercising was administered only to patients who expressed a wish to exercise more (list developed by experienced physiotherapists).

Criteria of overweight and obesity were derived from body mass index (BMI) formulae and calculated from measured height and weight. The Canadian Guidelines for Body Weight Classification was used for categorizing obesity $(\mathrm{BMI} \geq 30)$ and overweight $(25<\mathrm{BMI}<30)^{30}$.

\section{Statistical Analysis}

Demographic and clinical characteristics of DM1 patients are presented with the mean, standard deviation (SD) and range for continuous variables, and frequency and percentage for nominal and categorical variables. Comparisons between mild and classic phenotypes were performed with $\chi 2$ tests with the Yate's correction for continuity for 2 X 2 tables and with the Student ttests for continuous variables. All statistical analyses were performed with the SPSS package (11.0, SPSS, Chicago, Ill).

\section{Results}

\section{Characteristics of participants}

Patients with the mild phenotype were older than those with the classic phenotype (Table 1). The economic status differs between patients with classic and mild phenotypes: despite no significant differences in education, those with the classic phenotype present a lower annual family income and a higher rate of reliance on social assistance.

Results showed that over $50 \%$ of DM1 patients are overweight or obese, $23.6 \%$ are regular smokers, and $76 \%$ are physically inactive (Table 2). Except for overweight and obesity, significant differences were observed between patients with classic and mild phenotypes for all the other lifestyle risk factors: those with the classic phenotype are more often regular smokers, consume illicit drugs more often and are less physically active.

The mean BMI of the total sample was 26.0 (standard deviation 5.7). Although no difference between the BMI patients with classic and mild phenotypes was observed, analysis by 
Table 1: Demographic, socioeconomic and clinical characteristics of patients with classic and mild DM1 phenotypes

\begin{tabular}{lllll}
\hline & $\begin{array}{c}\text { Total group } \\
(\mathrm{n}=200)\end{array}$ & $\begin{array}{l}\text { Classic phenotype } \\
(\mathrm{n}=158)\end{array}$ & $\begin{array}{l}\text { Mild phenotype } \\
(\mathrm{n}=42)\end{array}$ & $\mathrm{p}$-value \\
\hline Age, mean (SD) & $47.0(11.8)$ & $44.3(9.2)$ & $57.4(14.4)$ & \\
Range & $20-81$ & $20-71$ & $32-81$ & 0.001 \\
Gender, n (\%) & $79(39.5)$ & $62(39.2)$ & $17(40.5)$ & n.s. \\
Men & $809(529)$ & $981(452)$ & $162(180)$ & \\
CTG, mean (SD) & $50-2200$ & $125-2200$ & $50-1000$ & 0.001 \\
Range & & & & \\
Annual family income*, n (\%) & $33(16.5)$ & $30(19.0)$ & $3(7.1)$ & \\
$<10,000$ & $70(35.0)$ & $66(41.8)$ & $4(9.5)$ & \\
$10,000-19,999$ & $38(19.0)$ & $21(13.3)$ & $17(40.5)$ & $<0.001$ \\
$20,000-39,999$ & $20(10.0)$ & $13(8.2)$ & $7(16.7)$ & \\
$40,000-49,999$ & $21(10.5)$ & $11(7.0)$ & $10(23.8)$ & \\
$>60,000$ & $18(9.0)$ & $17(10.8)$ & $1(2.4)$ & \\
Unknown/refused & $85(43.0)$ & $84(53.0)$ & $1(2.0)$ & $<0.001$ \\
Social assistance, n (\%) & & & & \\
Education, $\mathrm{n}(\%)$ & $109(54.5)$ & $88(55.7)$ & $21(50.0)$ & \\
$<$ High school & $60(30.0)$ & $48(30.4)$ & $12(28.6)$ & $\mathrm{n}$. .s. \\
High school & $27(13.5)$ & $19(12.0)$ & $8(19.0)$ & \\
College & $4(2.0)$ & $3(1.9)$ & $1(2.4)$ & \\
University & & &
\end{tabular}

$*$ Can\$; n.s. $=$ p $>0.05$

gender showed that, among women with the classic phenotype, $44.8 \%$ presented excess weight as compared to $24.0 \%$ among those with the mild phenotype $(\mathrm{p}=0.03)$. For men, the BMI was similar for patients with the classic and mild phenotypes $(\mathrm{p}=$ 0.82 ) with an excess weight in $54 \%$ of patients.

Also it was found that a large proportion of inactive DM1 patients wished to perform more physical activities. From a predetermined list of reasons, physical problems, fatigue, lack of money and lack of nearby facilities were the most common reasons evoked for being physically inactive (Table 3). Most reasons for not doing physical activities are similar between the two phenotypes except for patients with the mild phenotype more often reporting lack of time as a reason and patients with the classic phenotype reporting more frequently lack of help as a reason.

All 14 illicit drug users were cannabis consumers and one of them also reported LSD consumption during the last year. All of them had the classic phenotype. From the 158 participants with the classic phenotype, $5.1 \%$ are regular users (at least once a week) and $3.8 \%$ are occasional users (less than once a week). Self-reported excessive alcohol consumption was present in only seven participants.

Table 2: Prevalence of lifestyle risk factors in DM1

\begin{tabular}{|c|c|c|c|c|}
\hline & $\begin{array}{l}\text { Total group } \\
(\mathrm{n}=200)\end{array}$ & $\begin{array}{l}\text { Classic phenotype } \\
(\mathrm{n}=158)\end{array}$ & $\begin{array}{l}\text { Mild phenotype } \\
(\mathrm{n}=42)\end{array}$ & \\
\hline & $\mathrm{N}(\%)$ & $\mathrm{N}(\%)$ & $\mathrm{N}(\%)$ & p-value \\
\hline \multicolumn{5}{|l|}{ Overweight \& Obesity } \\
\hline Obesity (BMI $\geq 30$ ) & $42(21.0)$ & $35(22.2)$ & $7(16.7)$ & \multirow{2}{*}{ n.s. } \\
\hline Overweight $(25<\mathrm{BMI}<30)$ & $65(32.5)$ & $52(32.9)$ & $13(31.0)$ & \\
\hline \multicolumn{5}{|l|}{ Tobacco smoking } \\
\hline Regular smokers (everyday) & $47(23.6)$ & $40(25.3)$ & $7(17.1)$ & \multirow{2}{*}{0.05} \\
\hline Occasional smokers & $13(6.5)$ & $7(4.4)$ & $6(14.6)$ & \\
\hline Illicit drug consumption & $14(7.0)$ & $14(8.9)$ & $0(0.0)$ & 0.03 \\
\hline Excessive alcohol consumption & $7(3.5)$ & $5(3.2)$ & $2(4.8)$ & n.s. \\
\hline \multicolumn{5}{|l|}{ Physical inactivity } \\
\hline $\begin{array}{l}\text { Exercise less than three times per week } \\
(20-30 \text { minutes })\end{array}$ & $152(76.0)$ & $130(82.3)$ & $22(52.4)$ & $<0.001$ \\
\hline Wish to do more exercise & $137(68.5)$ & $120(75.9)$ & $17(40.5)$ & $<0.001$ \\
\hline
\end{tabular}


Table 3: Self-reported reasons for physical inactivity in DM1

\begin{tabular}{|c|c|c|c|}
\hline Reason invoked & $\begin{array}{l}\text { Total group } \\
n=137 \\
n(\%)\end{array}$ & $\begin{array}{l}\text { Classic } \\
n=120 \\
n(\%)\end{array}$ & $\begin{array}{l}\text { Mild } \\
n=17 \\
n(\%)\end{array}$ \\
\hline Physical problems & $93(68.0)$ & $84(70.0)$ & $9(52.9)$ \\
\hline Fatigue & $47(34.0)$ & $40(35.1)$ & $7(46.7)$ \\
\hline Lack of money & $44(32.0)$ & $42(35.0)$ & $4(23.5)$ \\
\hline Lack of nearby facilities & $43(31.0)$ & $39(32.5)$ & $4(23.5)$ \\
\hline Lack of help & $37(27.0)$ & $36(30.0)$ & $1(5.9)$ \\
\hline Lack of time & $33(24.0)$ & $25(20.8)$ & $8(47.1)$ \\
\hline Unadapted facilities, equipment or program & $33(24.0)$ & $32(26.7)$ & $1(5.9)$ \\
\hline Shyness or unease to perform & $31(23.0)$ & $30(25.0)$ & $1(5.9)$ \\
\hline Lack of transport & $29(21.0)$ & $28(23.3)$ & $1(5.9)$ \\
\hline Lack of family support & $16(12.0)$ & $16(13.3)$ & $0(0)$ \\
\hline Need technical aids & $3(2.0)$ & $3(2.5)$ & $0(0)$ \\
\hline
\end{tabular}

\section{Discussion}

\section{Lifestyle habits in DM1}

Overweight and obesity. The proportion of DM1 patients with obesity $(21 \%)$ is higher than in the regional reference population (Saguenay-Lac-St-Jean, Québec, Canada) $(13.9 \%)^{31}$ and the proportion of those who are overweight $(32.5 \%)$ is slightly lower $(36.0 \%)^{31}$. The present results are in accordance with previous observations that DM1 patients constitute a population which exercises less and has a higher fat and carbohydrate intake than the daily intake recommendation ${ }^{32}$. Although patients with the classic phenotype exercise less than those with the mild phenotype, the proportion of DM1 patients with obesity or overweight conditions is similar for the two phenotypes. The comparison with the trend in the Canadian population is difficult to make as prevalence of obesity increases with age until 65 years and then tend to decrease. Considering that the mild phenotype has a mean age of 57 years, it could be explained by an age factor but other factors could come into play. In addition, the standard anthropometric measures such as BMI may have less clinical meaning in DM1 than in the general population. In cases of reduced muscular mass such as in the DM1 population, the BMI would tend to underestimate the prevalence of obesity and waist circumference could represent a better marker of abdominal fat accumulation ${ }^{33}$. However, as the abdominal muscles are weak in DM1, it is not clear if waist circumference would be a more reliable measure of obesity than BMI.

The prevention of obesity is particularly important in DM1 as almost all patients are affected at a certain level by a metabolic syndrome, including abnormalities in fat metabolism and body fat distribution, insulin resistance, elevated glucose and dyslipidemia (hypertriglyceridemia and low HDL-cholesterol levels) ${ }^{14,34}$.

Poor diet choice has been previously described in neuromuscular disorders ${ }^{35}$ and may contribute to the high prevalence of overweight and obesity recorded in DM1. In the general population, the highest rates of obesity occur among population groups with the highest poverty rates. Poverty and food insecurity (limited or uncertain availability of nutritionally acceptable or safe foods) ${ }^{36}$ are associated with lower food expenditures, low fruit and vegetable consumption, and lowerquality diets, where peoples tend to ingest inexpensive energydense foods (sugar and fat combination) ${ }^{36}$. This type of food is readily available as processed food, which may compensate for expressed difficulties (lower strength, planification, etc.) related to cooking tasks and is often cheaper than healthier food choices $^{37}$. One study has explored a one-time dietary intervention followed by phone counselling once a week among neuromuscular patients including DM1; it has showed a modest but interesting effect over a 12 months period on caloric intake ${ }^{37}$.

Tobacco smoking. The prevalence of tobacco smoking $(30.1 \%)$ is higher in DM1 than that observed in the regional population $(24.20 \%)^{31}$ or in the province of Quebec population $(25 \%)$. We found a significantly higher smoking rate among patients with the classic phenotype than among those with the mild phenotype. As in the general population ${ }^{23}$, it could partly be explained by the relationship between socioeconomic deprivation and higher rates of smoking and between age and smoking cessation, in the context that mild phenotype patients were older. Respiratory disorders (pneumonia, chronic respiratory failure) followed by cardiac disease are the leading causes of death in DM1 ${ }^{38}$. Brief and intensive interventions to be administered by healthcare professionals are available from national anti-smoking agencies and should be integrated into the health care management plan for this population.

Physical inactivity. A majority of DM1 patients (76\%) are physically inactive as compared to the reference population $(47.9 \%)^{31}$. Patients with the classic phenotype are significantly less active than those with the mild phenotype, although the latter are older. Several personal and environmental factors reported by the patients explain this situation including physical problems, fatigue, lack of money, lack of nearby facilities and lack of help. Using the LIFE-H questionnaire ${ }^{39}$, we previously showed that $37.3 \%$ of the patients with the classic phenotype reported "needing help" or "not accomplishing activities" related to the practice of physical activities to maintain their fitness as compared to $1.0 \%$ in patients with the mild phenotype ${ }^{10}$. We also reported that more than one third of patients were highly dissatisfied regarding their participation in physical activities ${ }^{10}$. Other features specific to DM1 such as lack of motivation and daytime sleepiness may play a role ${ }^{40}$ as well as living in a 
disadvantaged milieu where low practice of physical activities is usually observed.

Although several obstacles are present, potential benefits of physical activities should not be overlooked and should be promoted in the DM1 population. Exercise and aerobic capacity programs have been recommended in neuromuscular disorders in order to improve or preserve muscle function and to prevent or reduce secondary problems such as pain or fatigue ${ }^{41-43}$. In view of the prevalence of excessive weight, the practice of physical activities could also prevent further weight gain or even promote weight loss. According to a recent Cochrane review, patients with neuromuscular disorders should be advised that normal participation in moderate-intensity strength training appears not to be detrimental ${ }^{44}$.

Alcohol consumption and illicit drug use. Excessive alcohol consumption was reported by only $3.5 \%$ of DM1 patients while $8.9 \%$ of the reference population reported excessive alcohol consumption $^{45}$. Illicit drug use was also marginal among our total sample $(7 \%)$ and exclusively found among the classic phenotype. This rate is below that observed in the province of Quebec population $(13 \%)^{46}$ although socioeconomic deprivation has been shown to increase the risk of dependence on alcohol and drugs ${ }^{23}$.

\section{Health promotion in DM1}

Factors influencing adoption of healthy lifestyle habits in DM1. Many health and social characteristics of DM1 may interfere with health promotion behaviours. Common DM1 symptoms such as lower limbs weakness, fatigue, daytime sleepiness, pain, apathy, frontal cognitive deficits, lower intellectual functioning and some personality traits may represent barriers to commitment in health promoting behaviours. In addition, personal factors such as acceptance of the disease and self-efficacy may also influence the engagement in health-promoting behaviours ${ }^{15}$.

In the general population, unhealthy lifestyle habits are known to be more prevalent among populations demonstrating poor socioeconomic conditions ${ }^{47}$. Patients with DM1 frequently show poor academic achievement, high unemployment, low family income, and high reliance on social assistance ${ }^{12}$. Myotonic dystrophy type 1 was found to be six times more prevalent in disadvantaged neighbourhoods compared with advantaged ones ${ }^{48}$. Such a residential segregation contributes to social exclusion and isolation and individuals with less social and emotional support from others would be more likely to experience lower well-being, as well as higher depression rate, and greater levels of disability from chronic diseases.

The autosomal dominant mode of inheritance of DM1 also contributes to this concentration effect; many affected relatives live together in the same house. This familial aggregation as well as the residential segregation could play a role in the limitation of the promotion of education and the lack of support to adopt healthy lifestyle habits. Yet, it is not clear whether socioeconomic factors contribute more to unhealthy lifestyle habits than the health impairments themselves; their respective roles are difficult to ascertain in DM1 as patients with a higher socioeconomic status are those with fewer symptoms. Thus, rationale and concerns about developing health promotion interventions among this population should take into account all the aspects of the disease, including characteristic impairments and disabilities as well as its socioenvironmental factors.

\section{Limits of the study}

The results are indicative of the French Canadian population of Québec, but may not be generalizable to other populations. The results are also self-reported for the most part and may not reflect properly the actual situation due to social desirability or memory bias.

\section{Conclusion}

Myotonic dystrophy type 1 patients present several risk factors, namely greater tobacco smoking, physical inactivity and obesity and overweight. All healthcare professionals involved in the clinical services dedicated to DM1 patients must be aware of these risk factors in order to address more efficiently patients' concerns and to favour health promotion. However, the expected poor adherence to healthy lifestyle behaviours should gear research toward developing adequate education strategies taking into consideration the complexity of the disablement and the social environment of DM1 patients.

\section{Funding}

CG hold a career-grant funding from Fonds de recherche en santé du Québec. This research was made possible by a grant from the Canadian Institutes of Health Research and Muscular Dystrophy Canada.

\section{REFERENCES}

1. Emery AE. Population frequencies of inherited neuromuscular diseases: a world survey. Neuromuscul Disord. 1991;1(1):19-29.

2. Mathieu J, De Braekeleer M, Prévost C. Genealogical reconstruction of myotonic dystrophy in the Saguenay-LacSaint-Jean area (Quebec, Canada). Neurology. 1990 May;40(5): 839-42.

3. Fu YH, Pizzuti A, Fenwick RG, Jr., et al. An unstable triplet repeat in a gene related to myotonic muscular dystrophy. Science (New York, NY. 1992 Mar 6;255(5049):1256-8.

4. Harper P. Myotonic dystrophy : a multisystemic disorder. In: Harper P, Van Engelen B, Eymard B, Wilcox D, editors. Myotonic Dystrophy: present management, future therapy. Oxford: Oxford University Press; 2004. p. 3-13.

5. Mathieu J, Boivin H, Richards CL. Quantitative motor assessment in myotonic dystrophy. Can J Neurol Sci. 2003 May;30(2): 129-36.

6. Laberge L, Begin P, Richer L, Jean S, Mathieu J. Fatigue and daytime sleepiness in patients with myotonic dystrophy type 1 : to lump or split? Neuromuscul Disord. 2009;19(6):397-402.

7. Meola G, Sansone V, Perani D, et al. Executive dysfunction and avoidant personality trait in myotonic dystrophy type 1 (DM-1) and in proximal myotonic myopathy (PROMM/DM-2). Neuromuscul Disord. 2003 Dec;13(10):813-21.

8. Antonini G, Soscia F, Giubilei F, et al. Health-related quality of life in myotonic dystrophy type 1 and its relationship with cognitive and emotional functioning. J Rehabil Med. 2006 May;38(3): 181-5.

9. Gagnon C, Mathieu J, Jean S, et al. Predictors of disrupted social participation in myotonic dystrophy type 1. Arch Phys Med Rehabil. 2008;89(7):1246-55.

10. Gagnon C, Mathieu J, Noreau L. Life habits in myotonic dystrophy type 1. J Rehabil Med. 2007 Sep;39(7):560-6.

11. Gagnon C, Noreau L, Moxley RT, et al. Towards an integrative approach to the management of myotonic dystrophy type 1 . J Neurol Neurosurg Psychiatry. 2007 Aug;78(8):800-6. 
12. Laberge L, Veillette S, Mathieu J, Auclair J, Perron M. The correlation of CTG repeat length with material and social deprivation in myotonic dystrophy. Clin Genet. 2007 Jan;71(1): 59-66.

13. Perron M, Veillette S, Mathieu J. [Myotonic dystrophy: I. Socioeconomic and residential characteristics of the patients]. Can J Neurol Sci. 1989;16(1):109-13.

14. Gagnon C, Chouinard MC, Jean S, et al. Health supervision and anticipatory guidance in adult myotonic dystrophy type 1 . Neuromuscul Disord. 2010 July 7;20(12):847-51.

15. Stuifbergen AK, Rogers S. Health promotion: an essential component of rehabilitation for persons with chronic disabling conditions. ANS Adv Nurs Sci. 1997 Jun;19(4):1-20.

16. Gagnon C, Chouinard M, Lavoie M, Champagne F. Analyse du rôle de l'infirmière dans le suivi des personnes atteintes de maladies neuromusculaires. Can J Neurosci Nurs. 2010;32(4):22-30.

17. World Health Organization. Ottawa Charter for Health Promotion. Health Promotion. 1986;1(4):iii-v.

18. Pender NJ. Health Promotion in Nursing Practice. 2nd ed. Stamford: Appleton \& Lange; 1987.

19. Stuifbergen AK, Seraphine A, Harrison T, Adachi E. An explanatory model of health promotion and quality of life for persons with post-polio syndrome. Soc Sci Med. 2005 Jan;60(2):383-93.

20. Harrisson T. Health promotion for persons with disabilities : What does litterature reveal? Fam Community Health. 2006;29(1S): $12 \mathrm{~s}-9 \mathrm{~s}$.

21. Stuifbergen AK. Building health promotion interventions for persons with chronic disabling conditions. Fam Community Health. 2006 Jan-Mar;29(1 Suppl):28S-34S.

22. Stuifbergen AK, Becker H, Blozis S, Timmerman G, Kullberg V. A randomized clinical trial of a wellness intervention for women with multiple sclerosis. Arch Phys Med Rehabil. 2003 Apr;84(4): 467-76.

23. Wilkinson R, Marmot M. Social determinants of health: the solid facts. 2nd ed. Copenhagen (Denmark): World Health Organization; 2003.

24. Aitkens S, Kilmer DD, Wright NC, McCrory MA. Metabolic syndrome in neuromuscular disease. Arch Phys Med Rehabil. 2005 May;86(5):1030-6.

25. Koch MC, Grimm T, Harley HG, Harper PS. Genetic risks for children of women with myotonic dystrophy. Am J Hum Genet. 1991 Jun;48(6):1084-91.

26. Mathieu J, Boivin H, Meunier D, Gaudreault M, Begin P. Assessment of a disease-specific muscular impairment rating scale in myotonic dystrophy. Neurology. 2001 Feb 13;56(3): $336-40$.

27. Direction Santé Québec. Enquête générale sur la santé et le bienêtre de la population. Québec: Institut de la statistique du Québec; 1998.

28. Direction Santé Québec. L'Enquête québécoise sur les limitations d'activités 1998 Québec: Institut de la statistique du Québec; 1998.

29. Educalcool. Les niveaux de consommation d'alcool à faible risque 2-3-4-5-0. Montréal: Educalcool; 2007.

30. Santé Canada. Canadian guidelines for body weight classification in adults. Ottawa; 2003

31. Bergeron A, Clouston M-C, Couture R, Duplain M, Lapierre R. Enquête de santé du Saguenay-Lac-St-Jean 2007 - Rapport sommaire. Saguenay: Direction de la santé publique, Agence de santé et de services sociaux du Saguenay-Lac-St-Jean; 2007.
32. Motlagh B, MacDonald JR, Tarnopolsky MA. Nutritional inadequacy in adults with muscular dystrophy. Muscle Nerve. 2005 Jun;31(6):713-8.

33. Despres JP. Cardiovascular disease under the influence of excess visceral fat. Crit Path Cardiol. 2007 Jun;6(2):51-9.

34. Brisson D, Houde G, St-Pierre J, Vohl MC, Mathieu J, Gaudet D. The pleiotropic expression of the myotonic dystrophy protein kinase gene illustrates the complex relationships between genetic, biological and clinical covariates of male aging. Aging Male. 2002 Dec;5(4):223-32.

35. McCrory MA, Wright NC, Kilmer DD. Nutritional aspects of neuromuscular diseases. Phys Med Rehabil Clin N Am. 1998 Feb;9(1):127-43.

36. Drewnowski A, Specter S. Poverty and obesity: the role of energy density and energy costs. Am J Clin Nutr. 2004;79(1):6-16.

37. Kilmer DD, Wright NC, Aitkens S. Impact of a home-based activity and dietary intervention in people with slowly progressive neuromuscular diseases. Arch Phys Med Rehabil. 2005 Nov;86 (11):2150-6.

38. Mathieu J, Allard P, Potvin L, Prévost C, Bégin P. A 10-year study of mortality in a cohort of patients with myotonic dystrophy. Neurology. 1999 May 12;52(8):1658-62.

39. Gagnon C, Mathieu J, Noreau L. Measurement of participation in myotonic dystrophy: reliability of the LIFE-H. Neuromuscul Disord. 2006 Apr; 16(4):262-8.

40. Laberge L, Begin P, Dauvilliers Y, et al. A polysomnographic study of daytime sleepiness in myotonic dystrophy type 1 . J Neurol Neurosurg Psychiatry. 2009 February 11, 2009;80(6):642-6.

41. Cup EH, Pieterse AJ, ten Broek-Pastoor JM, et al. Exercise therapy and other types of physical therapy for patients with neuromuscular diseases: a systematic review. Arch Phys Med Rehabil. 2007 Nov;88(11):1452-64.

42. Cup EH, Pieterse AJ, Knuijt S, et al. Referral of patients with neuromuscular disease to occupational therapy, physical therapy and speech therapy: usual practice versus multidisciplinary advice. Disabil Rehabil. 2007 May 15;29(9):717-26.

43. Eagle M. Report on the muscular dystrophy campaign workshop: exercise in neuromuscular diseases Newcastle, January 2002. Neuromuscul Disord. 2002 Dec;12(10):975-83.

44. Voet NBM, van der Kooi EL, Riphagen II, Lindeman E, van Engelen BGM, Geurts ACH. Strength training and aerobic exercise training for muscle disease. Cochrane Database Syst Rev. 2010 January 20(1):CD003907.

45. Régie régionale de la santé et des services sociaux du SaguenayLac-St-Jean. Tableau synoptique des indicateurs socio-sanitaires par territoire: Le Québec, le Saguenay-Lac-St-Jean et ses territoires de CLSC. Chicoutimi: Direction de la santé publique, Régie régionale de la santé et des services sociaux du SaguenayLac-St-Jean,; 2003.

46. Comité permanent sur la toxicomanie. Le point sur la situation de la toxicomanie au Québec en l'an 2000 Montréal: Ministère de la Santé et des Services Sociaux; 2000.

47. Galobardes B, Costanza MC, Bernstein MS, Delhumeau CH, Morabia A. Trends in risk factors for the major "lifestyle-related diseases" in Geneva, Switzerland, 1993-2000. Ann Epidemiol. 2003 Aug:13(7):537-40.

48. Perron M, Veillette S, Mathieu J. La dystrophie myotonique: I. Caractéristiques socio-économiques et résidentielles des malades. Can J Neurol Sci. 1989 Feb;16(1):109-13. 